Reference $\quad$ NBS

NBSIR 85-3216

\title{
Intaglio Ink Considerations
}

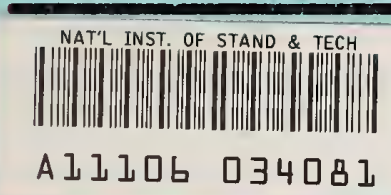

Brian Dickens

U.S. DEPARTMENT GF COMMERCE

National Bureau of Standards

Institute for Materials Science and Engineering

Polymers Division

Gaithersburg, MD 20899

August 1985

Prepared for:

Bureau of Engraving and Printing

'.S. Department of the Treasury

- () C ashington, DC 20228

100

.456

$85-3216$ 

INTAGLIO INK CONSIDERATIONS

Brian Dickens

U.S. DEPARTMENT OF COMMERCE

National Bureau of Standards

Institute for Materials Science and Engineering

Polymers Division

Gaithersburg, MD 20899

August 1985

Prepared for:

Bureau of Engraving and Printing

U.S. Department of the Treasury

Washington, DC 20228

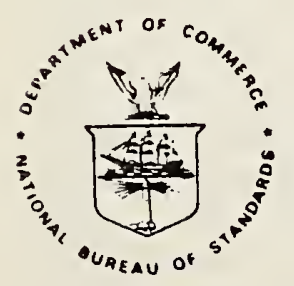

U.S. DEPARTMENT OF COMMERCE, Malcolm Baldrige, Secretary NATIONAL BUREAU OF STANDARDS, Ernest Ambler, Director 

B Dickens

Polymers Division

National Bureau of Standards

Gaithersburg, Md 20899

Table of Contents

1 Introduction $\quad \ldots \ldots \ldots \ldots \ldots \ldots \ldots \ldots \ldots \ldots \ldots$

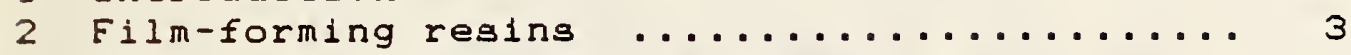

3 Intaglio printing ink vehicles ........... 6

4 Initiation systems for intaglio printing inks 7

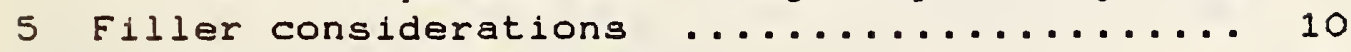

6 Pigment considerations ................. 12

7 Mechanism of cure for drying olls and alkyds 13

8 Resin considerations ................. 16

9 Solvent/dispersing phase considerations .... 17

10 Drying agent considerations ............. 20

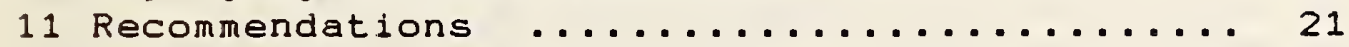

12 References ......................... 25

Abstract

Alkyds are recommended as the most practical resin system to polymerize in air. The alkyd should have a well-chosen molecular weight distribution and be dispersible in a water-containing solvent system. The solubility of oxygen in the ink formulations and solvent mixtures should be determined and the compositions adjusted to provide a level of oxygen which gives optimum cure. UV irradiation of the newly printed currency paper can probably be used to skin the ink rapidly and prevent blocking. This may allow printing of both sides of the currency paper in one pass. Replacement of the various pigments and fillers currently in use by dyes attached to the backbone of an organic polymer, either in water-soluble form or in the form of a glass should be investigated. The silica filler may be acting as a dessicant as well as a thickening agent. If this dessicant action is not important, thixotropy of the ink should be adjusted by using sodium carboxy methyl cellulose instead. Other recommendations are given and the formulation of intaglio printing inks is reviewed with special reference to BEP requirements. 
This report provides information on ways in which improved intaglio printing inks can be developed. Particular emphasis has been placed on the part of the ink which sets, i.e., the so-called vehicle or resin, on the ways in which setting of an ink can be induced, on ways in which the formulation of the ink may be expected to influence the setting reaction, and on the constraints imposed by the BEP printing presses. The goals are to help in the selection of a new ink vehicle which will perform satisfactorily on the presses at BEP, and to provide insight into other aspects of ink formulation and cure to reduce the spoilage in production runs. The ink setting reaction is a type of polymerization. Hence, polymerization reactions will be discussed first.

Many of the desirable properties of polymeric materials are conferred by the entanglement of the long polymer molecules with one another. Polymers are made by joining small molecules together to make long molecules.

In free radical polymerization, free radicals are generated and add to carbon-carbon double bonds in the small molecules (monomers). This effectively opens one of the two bonds in the carbon-carbon double bond in the small molecule. One of the bonds links the small molecule to the attacking radical, and the other becomes a new radical center which continues the linking process to other small molecules. When this process is repeated many times, a polymer is formed. The polymerization takes place at reasonably rapid rates at ordinary temperature because the free radicals used are extremely reactive and their reactions are very rapid.

Another way to make long chain molecules is to use reactants which each have two groups which enter into chemical reactions at moderature temperatures. This process is referred to as step-polymerization. Two different types of reactants may be used, such as a di-alcohol and a di-acid. Such bifunctionality would give long linear chains with the component molecules alternating. This class of reactions may be subdivided into those in which the molecules combine by rearrangement of atoms with no net loss of atoms from the molecular structure, and those in which the molecular rearrangement leads to the formation of two or more new molecules, one of which is the polymer or pre-polymer, and the other of which is some small molecule such as water.

Linear chains are expected to be soluble in a suitable solvent, and to melt if they are stable enough to withstand the necessary heat. A two-component reaction mixture in which one of the reactants is present in excess will give short chains, because the chain-forming process will end when one of the chain formers is used up. A reaction mixture of components with functionality greater than two will give chains with bonds to other chains, 
1.e., a three-dimensional network or cross-linked system. Cross-linked systems cannot be melted and are insoluble unless degraded into small molecules or broken at the interchain links.

A third polymerization process is to use ions in either anionic or cationic polymerization. To obtain good yields of polymeric material, low temperatures must generally be used, and the reactions are very easily stopped by traces of oxygen and water. The method is somewhat analagous to free radical polymerization, but the required conditions are so special that ionic polymerization will not even be considered here as a possibility for intaglio printing inks curing on large presses running in the open air.

The first two polymerization methods (i.e., free radicals and "normal" chemical reactions) of making polymers are routinely used to produce polymeric compositions for organic films and coatings. The resin supplier can draw on a wide range of possibilities when choosing the composition of the prepolymer molecules and the conditions of their preparation. Hence, resins can be designed and made in large variety. The problem is to design a method of polymerization and a resin which will give polymerization of the ink under the conditions imposed by the printing conditions.

Later sections of this report wlll discuss the constraints imposed on the formulation of intaglio inks by the necessity to polymerize the ink in the open air, and a recommendation for a polymerizable system will be given. In order to make clear which kinds of polymerization systems are in common use, a review will first be given of the simple resins on which more complicated formulations and mixtures are based.

The earliest polymeric system used in films and coatings was based on naturally available and slightly processed oils from various seeds, fruits, and nuts. Some of these oils "dry", that is, polymerize and become non-tacky, and some do not. Drying oils are usually heat-treated prior to application to increase their degree of polymerization. This increases the viscosity and decreases the drying time. The rate at which they dry depends on the number of active groups per molecule and on the rate of attack on these groups. The physical and chemical changes accompanying the drying of drying olls have been studied extensively. The reaction responsible for the drying process is a free radical reaction. In the normal mode of use, the free radicals are produced by the attack of the drying agents (certain metal salts) on hydroperoxide groups, which are only formed in the presence of oxygen. Drying oils are one of the few systems which polymerize satisfactorily in the presence of alr. 
Alkyds are modified drying oils and dry by the same mechanism. Different alkyds have different numbers of functional groups per molecule because they are made by modifying drying oil molecules or by joining two or more drying oil molecules together into more extended molecules. Also, chemical groups are incorporated into the alkyd molecule to confer such useful properties as dispersibility in water and resistance to weathering. Alkyds are extensively used in paints, for which there is an enormous market. Alkyd paint films do not survive severe weathering conditions, although they are appreciably more resistant than films based on simple drying oils. Acrylic and other vinyl components have been incorporated into alkyds to give better environmental resistance and to give a faster dry (by producing a material with a glass transition temperature near room temperature so that the material quickly becomes a glass rather than a sticky rubber). The various monomers may be chemically combined together to give an extended molecule or the alkyd can be physically mixed with an acrylic or similar polymer which is deposited unchanged on evaporation of the solvent.

Oxygen is needed in the drying of drying oils to produce hydroperoxide groups. In the drying oil polymerization mechanism, the hydroperoxide groups formed during the oxidation are decomposed by the driers to give more free radicals which continue the drying. This means that the drying reaction is autocatalytic, as will be explained in the sections on Initiation Systems and on Mechanism of Cure, and that the rate of drying increases with time, at least in the early stages. The usual situation in free radical polymerization is that the free radicals are initially generated from an added initiator, so that both the concentration of initiator and the rate of polymerization decrease with time. In general, oxygen inhibits free radical polymerizations because oxygen, when available, adds very quickly to the hydrocarbon free radicals on the polymerizing molecules $(20,000$ times more rapidly than the monomer does for methyl methacrylate) to give peroxyl radicals which are not as reactive as the original hydrocarbon radicals (Mayo et al., 1958a, 1958b, 1958c). Polymerization of drying oils using the relatively unreactive peroxyl radicals is possible only because drying oils contain very easily abstracted hydrogen atoms in the -CH2- groups next to the double bonds (see the section on Mechanism of (ure).

Where very easily abstracted hydrogen atoms are not available, which is the case for most materials, the peroxyl radicals attack the monomer molecules only very slowly. Peroxyl radicals on polymethyl methacrylate add to methyl methacrylate monomer at $1 / 60$ the rate of the parent hydrocarbon radicals. In most polymerizations, transformation of the original reactive hydrocarbon radicals into peroxyl radicals causes the polymerization reaction to slow down or stop. Most classes of free radical polymerization are significantly inhibited by oxygen, so oxygen must therefore be excluded as much as possible from the polymerization reaction. For these materials to be good 
candidates for use in intaglio inks, the rates of initiation would have to be high enough to consume all the oxygen already dissolved in the film and to carry the polymerization reaction to completion before much more oxygen could diffuse into the film and interfere. Initiation mechanisms are discussed in Section 4.

Polybutadiene and its derivatives are used to coat the inside of cans because they have good adhesion, good chemical resistance, and are without taste. These films form in free radical reactions in which carbon-carbon double bonds are opened to make new bonds which join previously separate molecules together. The carbon-carbon double bonds are not next to each other and the adjacent hydrogen atoms are relatively unreactive. Therefore, heat and a special catalyst are required to accelerate the particular chemical reaction of interest, and the reactions are easily poisoned by oxygen.

Unsaturated polyesters polymerize by the opening of double bonds in free radical reactions to give new bonds which become the backbone of the polymer chain. Often, the materials are used in a partially preformed state in a solvent which is itself polymerizable because it contains suitable double bonds, and the systems are known as "high solid" or "solventless" systems. The free radical reactions are strongly inhibited by oxygen.

The following polymerization reactions proceed by rearrangement of atoms, usually by moving a loosely bonded, or "active" hydrogen atom. Because free radicals are not involved, the reactions are relatively slow.

Epoxy resins are based on the cyclic epoxy group $-(\overline{\mathrm{CH}-\mathrm{O}-\mathrm{CH}})$, which can be opened in the presence of catalyst (both acids and bases have suitable catalytic activity). The epoxy group can combine with itself or extract labile hydrogen atoms from groups such as $-\mathrm{OH}$ (alcohol) and $=\mathrm{NH}$ (amine). Most epoxy resin systems consist of two components which are mixed just before use. One-component systems are available in which the activating species is chemically combined (or "blocked") to give an inactive form which can be reactivated by decomposition of the blocked group, either thermally or by hydrolysis by moisture in the surrounding air. The catalyst can also be blocked - the addition complex of a tertiary amine and boron trifluoride is stable at $25 \mathrm{C}$ but dissociates rapidly at $110 \mathrm{C}$ (Solomon, 1977, p195).

Polyurethanes are formed by addition of labile hydrogens (in $-O H$ or - NH- groups as mentioned above) to the isocyanate group $-(\mathrm{N}=\mathrm{C}=\mathrm{O})$ to give - $(\mathrm{NH}-\mathrm{CO}-\mathrm{O})$ - groups. One-component systems require chemical blocking of the active groups. Thirty minutes at $150 \mathrm{C}$ is typical of the reaction time required to unblock the system. 
Formaldehyde reacts with active hydrogen atoms in other molecules to give larger molecules. Its reactions with amine (-NH-) groups and $-\mathrm{OH}$ groups on phenols are extensively used to produce films. Melamine has six active hydrogen atoms per molecule and with formaldehyde gives stable, hard, and fast-drying films.

Films can also be formed without polymerization taking place in the film-forming step. Cellulosic derivatives and acrylates and other vinyl polymers are made prior to film formation, usually by free radical reactions in the absence of oxygen in the case of the vinyl type polymers, and are used as heat-softened, dispersed, or soluble materials which on cooling or evaporation of solvent give thin films. These materials are of relatively low molecular weight, and the film is in principle soluble.

Silicone groups also enter into reactions with various types of groups such as active hydrogens to give new chemical bonds which can be used to join molecules together, but these formulations are very expensive and are only used where the superior environmental resistance obtained is worth the extra expense (a factor of about 10 over the simple drying oils).

\section{Intaglio Printing Ink Vehicles}

Film-forming materials can be designed to contain reactive groups more or less as desired. The procedure is to design small molecules which contain groups necessary to confer the required properties in the finished film and groups which will allow the film to be polymerized. Resistance to exposure can be built in. Solubility or dispersibility in an appropriate solvent can usually be built in in the same way.

The polymerizable chemical groups in the small molecules are then activated or attacked and lead to chemical reactions which link the small molecules together to give larger molecules.

The first consideration for most formulations is that of cost. A very important second consideration for intaglio printing inks is environmental protection. Thus, the small molecules used should not be particularly combustible, volatile, or harmful, or even too unpleasant in odor.

For water-wipe systems, the ink should be water-dispersible from the wiping cylinder which removes excess ink from the engraved cylinder. This means that the small molecules should contain hydroxyl and/or carboxylic acid groups which are sufficiently polar to interact with water or with an aqueous solution of a base.

The next question is whether the ink should be cross-linked into a permanent film or deposited as an entanglement of more or less linear molecules. Intaglio printing is used for high quality 
printing, financial required. atter the usualiy of valuable documents such as currency and papers, and a permanent film is therefore usually

This means that some polymerization must take place ink has been applied.

The conditions of the polymerization are dictated by the nature of the substrate (rag-based paper for US currency at the present time) and the required speed of printing, which for currency is essentially to be as high as feasible. The only realistic possibility is to use free radicals. Free radicals are extremely reactive. They react so quickly that the fact that the temperature coefficients of free radical reactions are small is of no consequence. However, hydrocarbon free radicala combine very readily with oxygen when it is available and the resulting peroxyl radicals are much less reactive than the original hydrocarbon radical. Thus the high reactivity of hydrocarbon radicals is greatly reduced when they combine with oxygen.

The role of oxygen has to be established. Either the reaction is carried out so quickly that oxygen does not have time to interfere once the small quantity originaliy present in the ink components has been used up, or oxygen is used as a reactant. For oxygen not to interfere with a free radical polymerization, the initiation process must be very rapid and intense. When oxygen is a reactant, the initiation process must take place over a long period so that the needed oxygen can diffuse into the film. The appropriate rate of initiation depends on whether oxygen enters into the crosslinking (setting) reaction, in which case the rate of initiation should be slow so that enough oxygen will be available by diffusion into the ink layer from the surrounding air, or whether oxygen merely helps in the production of free radicals, which will combine with oxygen 1 f it is avallable or cause setting of the ink by crosslinking if it is not. In this second case, an intermediate rate of initiation is required.

\section{Initiation systems for intaglio printing inks}

Free radicals can be produced at enormous rates by the interaction of high energy radiation with the film-forming material. The rate of radical production is much greater than the rate of oxygen diffusion. Therefore, polymerizations which are poisoned by oxygen can be contemplated as candidates.

Electron beams tear organic materials apart to form free radicals. Because electron beams produce ozone from room air, they also require an inert atmosphere. Initiation by electron beam is therefore an option which is not particularly almple to implement. Gamma rays are readily absorbed by some chemical groups, which could be incorporated into the film-forming material, but they are so damaging and penetrating that very thick shielding is required to protect operating personnel. 
Microwaves (billions of hertz) and radiofrequencies (millions of hertz) act on polar and dipolar molecules to tumble them rapidly. This, then, is a method of selectively heating a component in the reaction mixture, in principle without limit on the amount of heat absorbed. Microwaves have been used to selectively decompose peroxyesters in prepolymer mixtures to effect polymerization (Menges et $a l ., 1980$ ) and to polymerize acrylates by irradiating the monomers (Teffal et al., 1983). One of the problems in the use of microwave and radiofrequencies in intaglio printing on paper is not to heat the water in the paper to unacceptable limits. Exploratory work will be necessary to find whether a suitable frequency domain exists to accomplish this. It is also uncertain whether thin films can be heated sufficiently by these frequencies to generate free radicals at the appropriate rate.

In the case of films which are somewhat transparent in the ultra-violet (UV) part of the electromagnetic spectrum, UV radiation can be used to break apart the more sensitive chemical groups and form free radicals, especially in thin films. Since printing inks are necessarily colored, and hence absorb visible and UV radiation very strongly, neither UV initiation nor visible light initiation is an attractive option for polymerization of these inks.

Cure of the surface of ink already in place on the currency paper using UV radiation could reduce or prevent sticking together of adjacent sheets of currency paper ("blocking" in the printing sense), which is a significant problem. Using UV radiation to decompose the surface hydroperoxide groups would give two free radicals per hydroperoxide group. Hydroperoxide groups absorb very weakly at about $320 \mathrm{~nm}$, which $1 \mathrm{~s}$ in the spectral range of medium pressure mercury lamps. In principle, the UV wavelength could also be chosen to break up the double bonds in the resin. However, these groups absorb at about $265 \mathrm{~nm}$ for three conjugated double bonds, and $225 \mathrm{~nm}$ for two conjugated double bonds. Radiation in this spectral region requires special care in handing. Cure of the surface using UV or visible light could also be effected by including a suitable photo-initiator in the ink formulation. This may be the most promising route to reducing spoilage from blocking.

The system used for initiation of polymerization should allow a storage time of at least two days (the real average storage time is more like eight days) at room temperature (which is often $30 \mathrm{C}$ ) and yet perform effectively at the temperature of cure (in the region of $70 \mathrm{C}$ to $80 \mathrm{C}$ for paper products) in the time allowed. Table 1 shows the Arrhenius parameters which such an initiation would need to have to be successful even under the rather favorable conditions detailed in Table 1. The necessary equations have been given by Pappas and Hill ( 1981 ). There is probably no feasible simple chemical reaction suitable for use as a printing system even under such idealized conditions because 
chemical reactions do not have sufficiently large pre-exponential coefficients. Additional work by Pappas et al. (1983, 1984) has concentrated on reactions which may be expected to have higher reaction rates, but sufficiently high rates are probably unattainable, especially in condensed phases. These considerations rule out systems which use simple combination of functional groups on the small molecules. For the same reason, unblocking of chemically blocked groups and generation of free radicals from an added initiator will not work.

Table 1 Arrhenius parameters needed for initiation system for two sets of cure requirements (after Pappas and Hill, 1981) case 1 storage press storage press

$\begin{array}{lrrrr}\text { \% cure } & 10 & 50 & 20 & 35 \\ \text { temperature } & 30 & 80 & 25 & 80 \\ \text { time, days } & 3 & 30 & 1.5 & 60 \\ \text { time, secs } & & 30\end{array}$

E (kcal/mole) 47

The most promising approach for the general in-depth polymerization of intaglio inks at the present time is to take advantage of the fact that free radicals can be produced over a long period of time in an auto-catalytic fashion and without the use of high energy radiation by using drying oil technology. The first necessity in designing the ink system is to overcome the limitations of conventional chemical systems in performing adequately in both storage and on the press. Using as the initiating species a group which is produced in the polymerization reaction means that the system will be auto-catalytic. It is this property which has made drying oils a viable system for film formation and in particular for intaglio inks. In the drying of drying oils, the hydroperoxides produced by the action of oxygen on hydrocarbon free radicals are decomposed by the driers into one free radical and one ion per hydroperoxide group. The hydroperoxide groups are formed in a repetitive step of the oxidation reaction. Hence, one free radical produces several hydroperoxide groups. Because these hydroperoxide groups later produce free radicals under the influence of the driers, the rate of polymerization accelerates with time. The newly applied ink can probably then be skinned using a medium pressure mercury lamp, which requires much less shielding than electron beams, or possibly using visible light, although the ink would then be slightly light-sensitive.

The second necessity in designing the ink system is to control the early effect of this free radical oxidation reaction, and hence stabilize the ink during pre-use storage. This may be done by including in the formulation a small quantity of antioxidant. which combines with free radicals containing oxygen, and which will soon be used up at the temperature of the printing press but 
which will last for days at room temperature. If an antioxidant which is volatile at the printing temperature is used, then its concentration will be depleted by evaporation as well as reaction. Methyl ethyl ketone oxime and butanal oxime are feasible candidates.

Polymers made by free radical processes or simple addition processes contain molecules with a range of molecular weights. The population of polymer molecules is known as the molecular weight distribution of the polymer. The molecular weight distribution has been shown to have a very significant effect on the rate of formation and final properties of a film (Bobalek et al., 1964a, 1964b, Fletcher et al., 1964). As the molecules in the resin become larger, fewer bonds are needed to set the ink. Thus, inks containing large molecules set more quickly. At some point, the ink will become unstable. A resin system which allows fine-tuning of the molecular weight distribution should be used, and the influence of molecular weight distribution on the resin properties should be studied. A mixture of alkyds of the same chemical composition but with well-chosen molecular weight distributions is a good candidate.

Drying oils are not water-soluble because they do not contain groups which are sufficiently polar. Also, drying oils are known to continue oxidizing after they have become non-tacky, and this further oxidation eventually causes deterioration in the film. Therefore, the number of oxidizable groups should be just sufficient to give an acceptable drying. Polar groups and durability can be added to drying oils by making them into alkyds. Therefore an alkyd is the material of choice as an intaglio ink vehicle. Because alkyds are used in the paint industry, there seems no danger of shortages in supply. Also, since well-controlled changes can be made in the functionality (number of potential polymerizable links per molecule) of the drying oils as they are made into alkyds, the fatty acid components can be adjusted more or less at will to control drying and the likelihood of further oxidative degradation. Thus, molecules which are larger than modified drying oils can be prepared with consistent properties. Fewer bonds are needed to link them into a three-dimensional network. Hence, an alkyd can easily be made which will dry more quickly than a drying oil.

\section{Filler Considerations}

Fillers, or extenders, were originally added to coatings such as paints to add volume to the dried film. It is now recognized that they also contribute to such properties of the final film as sheen, film reinforcement, and hiding background details which would otherwise been visible through the film. Finally, they reduce the cost of the film. In inks, solids are added to control viscosity, improve the ability to wipe the ink off the engraved cylinder, and provide the desired color. 
Amorphous silica, calcium carbonate, and barium sulfate are the main fillers and extenders used in BEP intaglio inks. (Definitions of filler, extender and inert pigments and a short survey of their characteristics are given in Stoy and Brown (1982): pigments will be discussed in the next section). One form of amorphous sllica is pyrogenic (fumed) silica, which is made from volatilized sand. The material is relatively free from impurities, such as metal ions, which would affect the setting reaction of the resin. It readily takes up water, which affects its adhesion to the resinous component of the ink. The hydration of the surface produces sllonol groups, which combine with alcohols and amines. Removal of this water by heating causes condensation of the silica particles with one another to give larger particles. A little-recognised property of the silica is that in non-aqueous formulations it keeps the other components of the inte dry.

Another form of amorphous silica is dehydrated gel. The gels are formed by acidification of aqueous silicate solutions. Sillca gels made in this way contain large quantities of trapped water and metal ions, and are far from being pure or very reproducible.

The viscosity of ink or paint thickened with sillca changes with time (L1ppe, 1969, 1976). The viscosity-thickening effect of sllica and the rate of change of this effect with time has been found (wason and Maisel, 1981, 1983) to depend on the average size of the particles, the particle size distribution and the nature of the surface of the silica. They suggested that an average size of 1.8 microns with a range of sizes between 0.5 and 7 microns was desirable.

From the discussion given above, it is seen that silicas are a possible source of trouble, especially in water-based formulations. It may be appropriate to find a substitute material. Silica is added to liquids to make them thixotropic $v i s c o u s$ when flowing and free-standing when stationary. This means that they flow easily enough for use on the printing presses yet are able to form thick films after they have been deposited on the paper. This behavior is related to the extension of order through the liquid phase resulting from polarization and attraction of molecules in the liquid phase by the silica. When the mixture is at rest, the order builds up. When the mixture is disturbed, the order is destroyed, and the material flows easily with a viscosity somewhat related to the rate of shear. Thixotropy is a property of colloldal suspensions.

Various gelling agents can be used to confer thixotropic properties. When thixotropy is produced by including filler in the formulation, the more finely divided filler is more effective in conferring thixotropy but the solutions are more ungtable. In addition to silica, there are amine-treated clays and hydrogenated castor oil. Alkyds may be gelled by the 
incorporation of polyamides. Aqueous solutions and suspensions may be gelled by the addition of cellulose derivatives. One of the best is sodium carboxy methyl cellulose, although ethyl hydroxy ethyl cellulose has also been used. The cellulose derivatives do not confer thixotropic properties, but their solutions have a highly ordered structure which behaves somewhat similarly.

Barium sulfate and calcium carbonate are widely used as extenders in paints (Boxall et al., 1981), and are also used in BEP ink formulations. They are added to modify the flow and leveling properties of the liquid, and the mechanical, permeability and gloss properties of the resulting solid. Barium sulfate is more or less inert, but, because of its high density, tends to settle out of thin formulations. Calcium carbonate is more unstable, and combines readily with fatty acids to give water-insoluble salts. The surface of calcium carbonate is appreciably changed by the absorption of atmospheric water (Solomon et al., 1983 , p96). Water-dispersible resins contain carboxyl groups, which with calcium carbonate in an aqueous environment would give a scum of insoluble calcium salts if the pH is not kept high by the presence of amine. This may lead to printing problems and it may be necessary to replace the calcium carbonate with a more inert material in a water-dispersible ink.

One possibility for a suitably inert material is a glassy organic polymer which is not swelled or hydrolysed by water. From this point of view, polystyrene is a good candidate, while polymethylmethacrylate is not. An extension of this idea is to use a mixture of resin which dries by polymerization and a material which simply dries by loss of solvent to give a film with a relatively high glass transition temperature. The advantages of this kind of approach were described by Ellis and Bakule (1982).

\section{Pigment Considerations}

Several BEP formulations contain pigments based on iron oxides. These inorganic solid materials are surface-hydrolyzed by atmospheric water. They act as drying agents (in some proportion to their surface area) in catalyzing the decomposition af the hydroperoxides formed in the drying step of drying oils and alkyds (Solomon et al., 1983, p100). Iron-containing soaps have little effect at room temperature, but are very reactive at baking temperatures (Whitaker, 1966).

The ink must be milled to disperse the pigments throughout the liquid phase, and must be cooled throughout the milling to reduce the effect of the curing reactions. Both the pigments and the fillers, especially carbon black, adsorb the drying agents, which must be added in considerable excess of the amounts needed to cure the neat resin. Most grades of carbon black seem to repress 
oxidative crosslinking reactions by functioning as antioxidants (Gruver and Rollmann, 1964). One of the few exceptions is graphitized channel black.

Some BEP inks currently contain organic dyes as well as inorganic plgments. It may be that inks which cure more reproducibly would be produced if the pigments were completely replaced by organic dyes. Certainly, the drying stage would then not be influenced by adsorption of drying agent, catalytic action of the pigments or antioxidant activity. The extensive miliing required to disperse solid inorganic pigments would not be needed. This would remove or reduce variability in the initiation period of the cure of the ink because fewer hydroperoxide groups would be produced during the mixing process.

The color of the dye depends on the interaction between the polarity of the dye and that of the matrix on the one hand, and the $\mathrm{pH}$ of the environment on the other. The dye must not change color in the weak acidic or alkaline environments conceivably met by currency during service. Leaching out of the dyes should not be a serious problem, because they can be attached to polymer backbones. For example, it may be possible to use as pigment an organic glass containing dissolved or grafted dyes. This is similar to the earlier suggestion of replacing the extenders with a chemically inert organic glass or with materials, such as the water-dispersed acrylics described by Ellis and Bakule (1982), which merely dry by evaporation but have a high glass transition temperature and therefore toughen the film, especially in the early stages.

\section{Mechanism of Cure for Drying Oils and Alkyds}

Because an alkyd system is the most viable ink resin material for BEP intaglio inks at the present time, a brief review of the cure mechanism will now be given. In one of the earliest systematic studies, some 24 aspects of the drying of drying oils were considered by the Research Committee of the Federation of Paint and Varnish Production Clubs (Bragdon, 1958), and most of these were characterized in considerable detail. In their publication, one can find details of the changes in drying oils during curing, for example, expansion, weight gain, spectrophotometric changes, oxygen penetration, oxygen uptake, and so on. oils containing various fatty acids were synthesized.

The chemical mechanisms of detail in the Encyclopedia of Polymer Science and Technology (Wiley, 1967) and in the Encyclopedia of Chemical Technology (3rd edition, Wiley, 1977). Other reviews include those by Sims and Hoffman (1962), Rheineck and Austin (1968), Solomon (1977), and wexler (1964). In addition, there is a large body of pertinent knowledge available from countless studies of oxidations of organic compounds. 
Most vegetable oils are glycerol esters of C18 fatty acids. There are three fatty acids per oil molecule. Those oils which contain unsaturated fatty acids, i.e., with carbon-carbon double bonds in the $\mathrm{C18}$ backbone, react with free radicals to form inter-fatty acid bonds. The double bonds activate the hydrogen atoms on the neighboring (allylic) $\mathrm{CH} 2$ group. Those $\mathrm{CH} 2$ groups which are between two double bonds are the most reactive. The double bonds themselves also undergo reaction, those in the cis configuration being more reactive than those in the trans configuration. Because the more easily extracted hydrogen atoms are next to carbon-carbon double bonds, the radical resulting from their extraction is stabilized by resonance over the neighboring double bond. During the later reaction of the radical, the most stable configuration is adapted, and the double bond is regenerated where possible so that it is conjugated with other double bonds.

The polymerization scheme for the setting reaction is essentially as follows. Hydroperoxide groups are inevitably formed during oxidation of the oil whenever the oil is in contact with air. These hydroperoxide groups are broken up by photolysia, heat, or the action of the drying agent, which is typically a transition metal ion in soluble organic form.

$$
\mathrm{R}-\mathrm{O}-\mathrm{O}-\mathrm{H}+\mathrm{CO}(2+)=\mathrm{R}-\mathrm{O}+\mathrm{O}+\mathrm{O}-\mathrm{H}(-)+\mathrm{CO}(3+)
$$

The drying agent has been reported (Girard, Beispiel and Bricker, 1965) to be regenerated by the reaction

$$
\mathrm{R}-\mathrm{O}-\mathrm{O}-\mathrm{H}+\mathrm{CO}(3+)=\mathrm{R}-\mathrm{O}-\mathrm{O} 0+\mathrm{CO}(2+)+\mathrm{H}(+)
$$

The hydrogen and hydroxyl ions form water, i.e.,

$$
\mathrm{H}(+)+\mathrm{O}-\mathrm{H}(-)=\mathrm{H} 2 \mathrm{O} \text {. }
$$

The radicals formed (shown with dots in the above equations) abstract a hydrogen atom from the allylic CH2 group or add to the double bond.

$$
\begin{aligned}
& \mathrm{R}-\mathrm{O} \cdot+-\mathrm{CH}=\mathrm{CH}-\mathrm{CH} 2-\mathrm{CH}=\mathrm{CH}-=\mathrm{R}-\mathrm{O}-\mathrm{H}+-\mathrm{CH}=\mathrm{CH}-\mathrm{C} \cdot \mathrm{H}-\mathrm{CH}=\mathrm{CH}- \\
& \mathrm{R}-\mathrm{O} \cdot+\mathrm{Q}-\mathrm{CH}=\mathrm{CH}-\mathrm{P}=\mathrm{R}-\mathrm{O}-(\mathrm{Q}) \mathrm{CH}-\mathrm{C} \cdot \mathrm{H}-\mathrm{P} \quad(\mathrm{P} \text { and Q are ends of the } \\
& \text { drying oil molecule). }
\end{aligned}
$$

The hydrocarbon radicals are peroxidized by rapid combination with molecular oxygen, which diffuses into the film from the air.

$$
-\mathrm{C} \cdot \mathrm{H}-+\mathrm{O} 2=-\mathrm{CH}-\mathrm{O}-\mathrm{O} \cdot
$$

The peroxyl radicals undergo several reactions, including hydrogen abstraction from the allylic group to form more hydroperoxide groups. The hydrogen on allylic groups is one of the few types of hydrogen that these relatively unreactive 
radicals can abstract.

This is the importance of the activated - CH2- groups in the fatty acid side chains. In this way, more initiating groups $(\mathrm{R}-\mathrm{O}-\mathrm{O}-\mathrm{H})$ are produced in a chain reaction, i.e., in a series of steps which is repeated several times, and the curing reaction accelerates. Cross-linking is accomplished by a radical on one fatty acid side chain adding to a double bond in a fatty acid in another oil molecule, viz.,

$-\mathrm{CH}=\mathrm{CH}-\mathrm{C} \cdot \mathrm{H}-\mathrm{CH}=\mathrm{CH}-\quad+\mathrm{P}-\mathrm{CH}=\mathrm{CH}-\mathrm{Q}=\mathrm{P}-\mathrm{CHR}-\mathrm{C} \cdot \mathrm{H}-\mathrm{Q}$,

where $\mathrm{R}=-\mathrm{CH}=\mathrm{CH}-\mathrm{C} \cdot \mathrm{H}-\mathrm{CH}=\mathrm{CH}-$, and $\mathrm{P}$ and $\mathrm{Q}$ are ends of the drying oil molecule. The second reaction involving the Ro' radical, given above, is another example of cross-linking.

When two peroxyl radicals meet, they interact. If there is a hydrogen atom bonded to the carbon atom on which the peroxide group is located, this interaction is usually terminating for the radicals. Both radicals cease to exist because a hydrogen atom is transferred from one to the other and a molecule of oxygen is produced (this is the mechanism of the Russell termination reaction). If there is no hydrogen atom available on the carbon atom to which the peroxide radical is attached, the interaction is non-terminating, and produces two highly reactive alkoxyl radicals and a molecule of oxygen. Although oxygen is produced in these interactions, it should be noted that two molecules of oxygen were originally consumed to produce the two peroxyl radicals. Whether alkoxyl radicals abstract hydrogen from their environment or undergo beta-scission to cut up the molecule depends mostly on their lifetime, which is almost always very short. The products of both possibilities are more likely to crosslink than the alkoxyl radicals are, and this may be an important source of the crosslinks which set the ink. Termination, or removal of radicals, also occurs by combination of two radicals to form a bond between the two parent species. This is more likely for hydrocarbon radicals than for peroxidized radicals, and therefore will occur mainly in the interior of the film, which is relatively sheltered from oxygen during the curing for fast-curing systems.

Thus, the film slowly oxidizes, cross-links, shrinks (because intermolecular distances of about $2.8 \mathrm{~A}$ are being replaced by covalent bond distances of about 1.5A), and hardens. Various small molecules escape from the film and, in the case of rapidly drying olls such as tung oil, puff up the film. These small molecules are water from the combination of hydrogen ions and hydroxyl ions produced from the hydroperoxide groups by the driers, and scission products from one of the reactions (the beta-scission reaction) undergone by alkoxyl radicals. The new bonds in the setting film are both oxygen-carbon bonds and carbon-carbon bonds, but not all these bonds contribute to crosslinking of the molecules in the ink. The nature of the crosslinks is not known. The range of reactions which occur is large. The importance of each reaction path in the overall setting of the film is governed by activation energies, reaction 
rates, temperature of cure, concentrations of reactive species, group mobilities, and the catalytic effects of driers, pigments, fillers and impurities. It is not worthwhile to attempt to give every possible reaction in this report.

\section{Resin Considerations}

In the earlier sections of this report, we have shown that the requirements of the intaglio printing system limit the resin system to an air-oxidation drying oil. The need for water dispersibility and, if feasible, use of water as solvent, strongly suggests the use of an water-dispersible alkyd as the resin component. The resin can be combined with other non-polymerizing materials, which are actually polymers themselves, to give the partially dried film more toughness and less tackiness than it would otherwise have. Ellis and Bakule (1982) described the addition of water-soluble acrylic resin to water-reducible alkyds to give a faster-drying tougher film. The acrylic component acts as an organic filler.

An interesting combination of allylic methylene (-CH2-) groups and acrylate groups in the same monomer molecule was reported by Larson and Emmons (1984), who described the polymerization of dicyclo pentenyl oxyethyl methacrylate. The compound polymerizes with alkyds, drying oils, and methacrylates, with or without air. In the drying oil-air oxidation mode, the molecular weight achieved was only 1000 to 2000, whereas when the material was polymerized in the methacrylate mode and initiated by UV irradiation, molecular weights over the range 10,000 to 1,000,000 were obtained. This difference was attributed by the authors to the higher radical density in the case of UV initiation, but is more likely to be the effect of the methacrylate radicals being far more reactive than the oxygen-containing radicals which cause the polymerization in the drying oil mode. Steric hindrance of the constrained dicyclo pentenyl moeity probably also slows down the drying oil reactions. Availability of oxygen is known to greatly retard the polymerization of methyl methacrylate (Mayo and Milier, 1958). It seems that the exterior of the material cured oxidatively and the oxygen-starved interior cured by methyl methacrylate polymerization reactions, which were initiated by free radicals diffusing in from the exterior layers. This effect begins to be important at thicknesses of greater than 50 microns ( $2 \mathrm{mils}$ ). It should also be noted that there was some problem with tackiness during the early stages of drying. The shelf life of the system was controlled by adding the volatile antioxidant methyl ethyl ketone oxime. The drying time of long oil alkyds was shortened from 5.5 hours to 3.5 hours by adding 10 to $30 \%$ content of the monomer to the alkyd.

It may be feasible to UV cure this material to give a solid skin by adding photoinitiators. This would dry the outer surface of the ink to a depth dependent on the levels of irradiation and 
added photoinitiator and the UV absorbance of the ink. The interior would then polymerize under oxygen starvation conditions (because oxygen would diffuse more slowly through a solid skin than through a fluid skin).

Holmberg and Johansson (1984) studied the effects of molecular weight distribution, hydroxyl group content, and double bond content on the viscosity and film properties of air-drying alkyd resins which they synthesized. The alkyd with the widest molecular weight distribution gave the hardest films. It also gave the most viscous solutions for a given weight of polymer, as expected, since it had the highest molecular weight material. Hydroxyl groups increased the viscosity (in xylene solution) by intermolecular hydrogen bonding, and double bond content decreased $1 \mathrm{t}$.

Kumanotani et al. (1984) studied the properties of colloidal alkyds. They had previously reported on the properties of alkyds with microgel content. These alkyds have fairly high molecular weights. The colloidal alkyds are of very high molecular weight (of the order of 1 million). Although these solutions are very viscous, the highest molecular weight resin gave the best film-forming results in all of the several tests they conducted. Nakayama, Watanabe, and Toyomoto (1984) described a high performance coating formulated from water-based emulsions and microgels stablized by a water-soluble air-drying resin.

Gooch et al., (1984) have studied the effect of auto-oxidative cross-linking, defined from the swelling behavior of the crosslinked polymer, of alkyds derived from vegetable oils. The alkyds were polymerized as emulsions in air and in pure oxygen. Crosslinking in air gave gas-filled voids which had deleterious effects on the mechanical properties. The emulsion materials dried much more rapidly in pure oxygen and had about $75-85 \%$ of the tensile strength of the film produced using metalic driers and at most $60 \%$ of the hardness. According to Gooch et al., the crosslinks include ester and ether bonds. The study was carried out to provide information on natural products, specifically soya bean oil. Commercial emulsions dried as well as the experimental materials and had much better properties.

Although water can probably be used as a dispersing agent for some alkyd formulations, it is probable that on the printing press water would not consistently evaporate at the right rate. The precise details are heavily dependent on the relative humidity of the air surrounding the press and the temperature of the press (Culver, 1982). A mixture of water and a "cosolvent" such as a glycol is an often-used compromise, but evaporation from cosolvent systems in which one component is water 13 also greatly affected by the relative humidity of the surrounding air (Culver, 1982). 
Since a resin used in new BEP intaglio inks would be water-compatible or at least water-dispersible, an appreciable part of the glycol content of the solvent would probably remain in the film and of course the glycol would not cure. Any glycol exuded from the film would probably make the film tacky.

Film-forming compositions which require a cosolvent for solubility crack as the solvent mixture becomes richer in water. This arises when the organic cosolvent evaporates at its usual rate but the high humidity hinders the evaporation of water. Moderately high molecular weight ethylene glycol monoethers are used as so-called "tail solvents" which are slow to evaporate. This ensures that the solvent mixture retains some organic solvent in situations where the humidity is so high that water evaporates only slowly.

A constant boiling mixture of water and one or two other materials where water forms a high percentage of the liquid would be an better candidate. However, most of the azeotropic mixtures have boiling points less than those of the components.

The following are water-containing azeotropes which have boiling points above that of water:

ethylene diamine $81.6 \%$ : water $18.4 \%, b$. pt. $=119 \mathrm{C}$
formic acid $\quad 77.5 \%$ : water $22.5 \%$, b. pt. $=107 \mathrm{C}$
hydrochloric acid $20.2 \%$ : water $79.8 \%$, b. pt. $=108.6 \mathrm{C}$
hydrobromic acid $47.5 \%$; water $52.5 \%$, b. pt. $=126 \mathrm{C}$

(Other acids also form azeotropic mixtures with water - the constant boiling mixture between hydrochloric acid and water was the first to be discovered and is used to provide analytical solutions of the acid in water.)

The acids would be incompatible with many fillers and pigments and dyes, and would degrade the paper currently in use. The diamine mixture contains so little water and so much organic material that it is not a worthwhile candidate.

An attractive choice to consider is to run the printing press in an environment with some appropriate combination of temperature and relative humidity so that water can be used undiluted. Once applied, the ink rapidly cools off, regardless of the temperature of application. As was pointed out above, the ink can probably be skinned by passing the sheets under a medium pressure mercury lamp. Another possibility is to heat and dry the water-containing ink using radio- or microwaves.

While water is very attractive as a solvent, there are many complications. Engel (1983) discussed problems arising from retention of the amine needed to solubilize or disperse the resin in water, high acid values from the acid groups added to the resin to confer solubility in water, solvent-resin interactions, 
viscosity-temperature behavior, and hydrolysis. The formation of resinous aggregates was suggested to occur at high water contents (Overton and Herb, 1983; Wicks, Anderson and Culhane, 1982). The appropriate temperature to use for water-containing formulations is not immediately obvious. Popping in the form of bubble formation in the setting $f 1 l \mathrm{~m}$ is a serious problem of water-based formulations of paints and baking enamels (Imai and Tsubouchi, 1980, Watson and Wicks, 1983). The cause seems to be retained water, which is harder to drive off than many organic solvents because of its higher heat of vaporization. There is an inverse relationship between the glass transition temperature of the resin system and the maximum film thickness obtainable blemish-free (watson and Wicks, 1983). Our own work has shown that water complexes the driers.

The questions of surface tension, viscosity control and evaporation of solvents from water-reducible, high solids coatings were investigated by Hansen (1984). Water-reducible means that although the polymer or pre-polymer is not itself soluble in water, it can be dispersed in water in the form of micelles, probably with the help of some other solvent or a complexing agent such as an amine. water itself and its dispersions have surface tensions much higher than the optimum for wetting the substrate. The surface tension can be reduced by adding suractants. Added polymer has a perturbing effect on the usual agents added to reduce surface tension in that it tends to absorb them (Hansen, 1977). Once the substrate has been wet, the surface tension of the ink serves to drag the ink into the pores of the substrate by capillary action and hence promotes adhesion. The viscosity of the ink must be kept in the appropriate range (about 5000 to $20,000 \mathrm{cp}$ ) while the fraction of the liquid which ends up as solid film should be as high as possible. This requires a solvent or, more usually, a solvent mixture that dissolves as much low and high molecular welght materlal as possible. Therefore, attention must be paid to the compatibility between the polymer, water, and any additives (Hansen, 1984) by considering their solubility parameters, which can be measured, but can also be estimated from activity coefficients. A considerable quantity of water would be absorbed from the ink by the paper.

In high solids formulations, or in the later stages of evaporation of solvent from most films, the evaporation of solvent is controlled by diffusion through the film. Changes in rates of evaporation have been quantified by Hansen (1968) and Ellis (1983). The rate of evaporation of solvent (Grant, 1981) has a complex effect on the properties of the drying film. Hansen (1984) points out that the effect of evaporation of the solubilizing amine from water dispersions of air-drying alkyds $1 \mathrm{~s}$ a neglected or unexplored area, and that retention of the amine lengthens the drying time (Dhein et al., 1978). Perera and Vanden Eynde (1983) have developed a method to measure the relationship between the stress in a coating and the evaporation of solvent. The stress is affected mostly by the rate of 
evaporation of the slowest evaporating solvent, and is least for the slowest evaporating solvent because the film then has time to undergo stress relaxation. Accumulated stress adversely affects cohesion of the film and adhesion to the substrate.

\section{Drying fgent (Drier) Considerations}

The generally accepted view of the action of the metal ion drying agents is that the metal ion changes valence to produce free radicals and ions from hydroperoxides. These reactions have been mentioned above in the section on Mechanism of Drying. To be effective, the metal ion must be in intimate contact with the drying oil (or alkyd). This means that it must be associated with an anion which is soluble in the resin. Naphthalates are usually used. Both cobalt and manganese are used for the metal component. Various other salts are sometimes added - their function seems to be to neutralize acid groups initially present and those formed during the oxidative cure reaction, and thus keep the driers in solution as the naphthalates. In addition, they may confer some crosslinking by ionic coordination to oxygenated groups formed in the ink by the air-oxidation process. Howvever, this would immobilize the active part of the drier and inhibit further setting. There is supposedly little effect of humidity on the action of the cobalt-manganese driers usually used (wexler 1964). As noted earlier, the iron oxide pigment also functions as a drier, especially in hot int.

Amines have been suggested as activators for the driers (Solomon, 1977, p56, and references therein). Amines are known to decompose hydroperoxides (Hiatt, 1971, and references therein), and this may be their mode of action. Thus, an alkyd solution containing an amine may cure more quickly than expected, and this kind of solution may also be advantageous from the point of retarding the evaporation of water. It should be noted that the metal salt driers give only one free radical per hydroperoxide group, whereas routes exist, as in UV photolysis for example, to break the hydroperoxide group into two radicals. The amine can be recovered unchanged when the reactions are carried out in dilute solution, yet the decomposition of the hydroperoxide is a free radical reaction. This suggests that the hydroperoxide has been decomposed catalytically into two free radicals and that amines may be very effective drying agents, even more so than metal salts, which produce only one free radical per hydroperoxide group. Hurley and Buono (1982) report that amines are known to complex cobalt driers (Morral, 1979) and to affect the reversibility of the trivalent to divalent cobalt transition (Laitinen and Kivalo, 1953). For the cobalt to act as a catalytic drier, it must cycle between these two valence states (Girard et al., 1965). 
Girard et al.

(1965) also showed that divalent cobalt aids the isomerism of double bonds in the oil molecules from the cis to the trans form, which they thought oxidized more quickly than the cis form. The action of drying agents is at best only partially understood.

Recommendations

1. The ink vehicle should be an alkyd because only molecules with allylic hydrogens will polymerize successfully in air. One possible candidate is the water-dispersible "Lustrasol 93-996" resin solution from Reichold Chemicals.

2. A second candidate would be a water-dispersible alkyd resin containing methacrylate groups, based on that described by Larson and Emmons. The polymerization of the methacrylate part will be poisoned by air, so a formulation based on this kind of resin could remain tacky. This depends on how much oxygen is available in the interior of the resin during setting. The oxygen content of the resin depends on the solubility of oxygen in the resin/waterlorganic solvent mixture and on the rate of the setting reaction, because the drying oil part of the molecule consumes oxygen as it sets. On the other hand, the drying oil part will not set without some oxygen being available, because oxygen is needed to produce more hydroperoxide groups which will then be decomposed by the drying agents to give the free radicals which drive the setting process. It is probably safer, more reasonable, and less fine-tuned (and hence less prone to variation) to rely exclusively on the drying oil mechanism and to select a candidate from the modified drying oil field.

3. From the points of view of reducing environment pollution, costs, and maintenance problems, the resins should be dispersible in water using the amine or ammonium salt as necessary. There are conflicting reports as to whether these amines retard setting. Ammonia is more volatile, and would retard the setting reaction less than the less volatile amines. However, fllms based on ammonium salts are known to discolor more rapidly than films based on higher amines. Fortunately, BEP's currency inks are dark in color, so this is probably not important in $B E P^{\prime} s$ application. Efforts should be made to decrease the press temperature during printing. This will decrease the rate of evaporation of water, which will make the behavior of the ink on the roller more stable.

4. Microwave and radiofrequency radiation could play an important part in evaporating the water from an ink dispersed in water. This would simultaneously heat the ink, dry $1 t$ and therefore make it more able to dissolve oxygen, and help it set. Dielectric measurements on the ink formulations and currency paper should be made to provide estimates of the efficacy of the process. Test cures should be carried out. 
5. The effect of water as solvent on the cure rate must be established. From the point of view of retarding the evaporation of water, decreasing the temperature will keep more water in the ink. This will also decrease the amount of oxygen able to dissolve in the ink because oxygen is less soluble in water than in most organic materials. From the point of view of oxygen solubility, decreasing the temperature will decrease the amount of dissolved oxygen, since oxygen solubility in organic materials generally increases with increasing temperature.

6. Investigations should be carried out to determine whether the solution thixotropy can be adjusted using sodium carboxy methyl cellulose instead of silica. The intended function of silica is to act as a thickening agent. Our very recent work suggests that a second function of silica is to act as a dessicant which dehydrates the ink by combining with any water present. The final effect of this is not yet known, although some considerations were given in paragraph 5 .

7. A replacement should be sought for the calcium carbonate extender. An organic extender such as polystyrene or sulfonated polystyrene should be considered, provided it can be safely and successfully mixed into the resin and the effect of the difference in refractive index of polystyrene from that of calcium carbonate can be tolerated.

8. A water-soluble acrylic or equivalent resin should be added to ink. This will impart a reasonably high glass transition temperature to the film in the early stages of drying to produce a tougher and more tack-free film.

9. The replacement of pigments by stable (and soluble) dyes should be investigated. This will reduce the necessity to mill the ink, and will make the cure more reproducible because the ingredients will be more easily dispersed.

10. The use of organic glasses containing the appropriate dyes grafted onto the polymer backbone should be explored. An extension of this scheme would be to consider currency note validation or even recognition schemes by automated equipment by including a fluorescent species on the polymer backbone. Unfortunately, practically all salts fluoresce strongly by emission from defects in the crystals and crystaliltes, and this aspect may not be worthwhile. Although a powerful fluorescer such as anthracene could maybe overpower most other fluorescers, one could conceivably change the apparent denomination of a bill (as read by a fluorimeter) by soaking it in an appropriate solution. 
11. Ink layers thicker than 2 mils (50 microns) cure slowly in the interior. UV initiation will probably be too slow beyond depths of about 10 microns in inks. The engavings should be deslgned so that they are as shallow as feasible, with 50 microns as the maximum depth.

12. A volatile oxime anti-oxidant such as methyl ethyl ketone oxime or butanal oxime should be added to the ink. This will retard the setting reaction until the ink is heated on the press.

13. The effect of molecular weight distribution of the resin in the uncured ink on the cure rate should be investigated. The molecular weight distribition can be adjusted by mixing two or more resins with different molecular weight distributions. It was shown in one investigation that adding $20 \%$ of a higher molecular weight material greatly decreases the drying time, in agreement with crosslinking theory. There is presumably a limit to the amount of high molecular weight material which can be added. As the molecular weight is inceased, fewer bonds will be needed to set the ink and the ink may become unstable.

14. Oxygen is needed for the cure of alkyds. Conversely, the ink is stable in the absence of oxygen. Oxygen is more soluble in solvents as the temperature is increased. Oxygen is less soluble in water than in many organic solvents. The solubility and diffusion rate of oxygen in the various solvent/dispersing agent formulations should be determined, and the effect of oxygen solubility on ink stability and cure should be established.

15. The UV absorption spectra of the curing resin and the mixed inks should be measured and used to determine the optimum wavelength at which to irradiate the newly printed ink in order to "skin" it using a photoinitiator and possibly allowing immediate printing on the other side.

16. The effect on the cure rate of skinning of the ink by irradiating to activate an added photo-initiator should be determined. Oxygen diffusion will probably be slowed down by a hard skin on the ink.

17. The action of amines on the cure must be clarified. There are conflicting reports on whether they accelerate the reaction or inhibit it. They seem to inactivate the cobalt drier.

18. The influence of viscosity-reducing agents added to the water dispersion of the ink on the cure rate should be clarified.

19. There is need for a better understanding of the action of the driers, in particular whether they "fix" oxygen as well as decompose hydroperoxide groups, whether they influence the reactivity of the carbon-carbon double bonds by producing trans configurations from cis configurations in the alkyd side chain, whether they are "consumed" by coordination to oxygenated groups, and whether they are poisoned by amines. 
E. G. Bobalek, E. R. Hoore, S. S. Levy, and C. C. Lee, "Some implications of the gel point concept to the chemistry of alkyd resins", J. Appl. Polym. Sci., 8, 625-657, 1964.

E. G. Bobalek and M. T. Chiang, "Synthesis and properties of some alkyds of more complex carboxyl functionality", J. Appl. polym. Sci., 8, 1147-1168, 1964.

J. Boxall and J. A. von Fraunhofer "paint Formulation, Principles and Practice", Industrial Press, New York, 1981.

C. R. Bragdon, Technical Editor, "Film Formation, Film Properties, and Film Deterioration, A Study by the Research Committee of the Federation of Paint and Varnish production Clubs", Wiley-Interscience, 1958.

L. J. Culver, "Organic solvent evaporation from aqueous compositions", Modern Paint and Coatings, October, 133, 1982.

R. Dhein, H. U. Pohl, and J. Schoeps, Farbe Lack, 84, 680, 1978.

W. H. Ellis, "Comparative solvent evaporative mechanisms for conventional and high solids coatings", J. Coat. Tech., 55, 63, 1983.

1. J. Ellis and R. D. Bakule, "Industrial waterborne acrylic polymers come of age", Mod. Paint and Coat., October, 156, 1982.

$\mathrm{J}$. J. Engel, "Problems of air-drying water borne alkyds", J. water Borne Coat., August, 3, 1983 .

J. R. Fletcher, L. Polgar, and D. H. Solomon, "Molecular weight distribution in alkyd resins. part 1", J. Appl. polym. Sci., 8, 659-671, 1964 .

T. A. Girard, M. Beispiel, and C. E. Bricker, "The mechanism of cobalt drier action", J. Am. Oil Chemists Soc., 42, 82, 1965 .

J. W. Gooch, G. C. Wildman, and B. G. Bufkin, "Auto-oxidative crosslinking of vegetable oils and alkyd emulsions", J. Coat. Tech., 56, 33, 1984 .

P. M. Grant, J. Coatings Techn., 53, 33, 1981.

J. T. Gruver and K. W. Rollmann, "Antioxidant properties of carbon black in unsaturated elastomers. Studies with cis-polybutadiene", J. Appl. Polym. Sci., 8,1169-1183, 1964.

C. M. Hansen, J. Oil Colour Chem. Assoc., 51, 27, 1968.

C. M. Hansen, Ind. Eng. Chem. Prod. Res. Dev., 16, 266, 1977. 
C. M. Hansen, "Solvents in coatings", in "Organic Coatings Science and Technology", G. D. Parfitt and A. V. Patsis, Eds., Vol. 6, Marcel Dekker, New York, 1984, pages 125-150.

R. Hiatt, "Hydroperoxides", Chapter 1 in "Organic Peroxides", Vol. II, D. Swern, Ed., Wiley-Interscience, New York, 1971.

K. Holmberg and J.-A. Johansson "High solids alkyd resins", in "Organic Coatings - Science and Technology", G. D. Parfitt and A. V. Patsis, Eds., Vol. 6, Marcel Dekker, New York, 1984, pages $23-34$.

R. Hurley and F. Buono, "Practical considerations in the drying of water-reducible alkyds", J. Org. Coat. Tech., 54, 55, 1982.

T. Imai and K. Tsubouchi, "Evaporation of solvents from water-borne systems during baking", J. Coat> Tech., 52, 71 , 1980 .

J. Kumanotani, H. Hata and H. Masuda, "Formation and properties of colloidal alkyds", in "Organic Coatings - Science and Technology", G. D. Parfitt and A. V. Patsis, Eds., Vol. 6. Marcel Dekker, New York, 1984, pages 35-54.

D. B. Larson and w. D. Emmons, "The Chemistry of high solids alkyd/reactive diluent coatings", in "Organic Coatings - Science and Technology", G. D. Parfitt and A. V. Patsis, Eds., Vol. 6, Marcel Dekker, New York, 1984, pages 1-34.

H. A. Laitinen and P. Kivalo "Polarographic reduction of hexamine cobalt(III) ion", J. Amer. Chem. Soc., 75, 2198, 1953.

R. J. Lippe, "A method of improving the stability of thixotropic epoxy resin compositions", Soc. Plastics Eng. Tech. Papers, Vol. XV, 66, 1969.

R. J. Lippe, "Some factors affecting thixotropy recovery states", Proc. 31st Annual Conference, Reinforced Plastics/Compsites Institute, Soc. Plast. Eng., Section 14-C, 1,1976 .

F. R. Mayo and A. A. Miller, "The oxidation of unsaturated compounds. VII. The oxidation of methacrylic esters"'J. Amer. Chem. Soc., 80, 2493-2496, 1958a.

F. R. Mayo, "The oxidation of unsaturated compounds. VIII. The oxidation of aliphatic unsaturated compounds", J. Am. Chem. Soc., 80, 2497-2500, 1958b.

F. R. Mayo, A. A. Miller, and G. A. Russell, "The oxidation of unsaturated compounds. IX. The effects of structure on the rates and products of oxidation of unsaturated compounds", J. Amer. Chem. Soc., 80, 2500-2507, 1958c. 
G. Menges, K. Kircher, and B. Franzkoch, "Crosslinkage of polyethylene in the UHF field, using t-butyl perbenzoate as energy absorber and radical former", Kunststoffe, $70,45-48$, 1980 .

F. R. Morral, "Cobalt compounds", Kirk-Othmer encyclopedia of chemical technology, Vol. 6, Wiley, New York, 1979.

Y. Nakayama, T. Watanabe, and I. Toyomoyo, "High performance coatings from blends of emulsions and water-soluble resing", $\mathrm{J}$. Coat. Tech., 56, 73, 1984.

J. R. Overton and C. A. Herb, "Colloid chemistry of water-reducible coatings, part 1: viscosity behavior", J. Org. Coat. Tech., 55, 33, 1983.

S. P. Pappas and L. W. Hill, "Kinetic parameter considerations for maximizing stability and minimizing cure temperature of thermosetting coatings", J. Coat. Techn., $53,43-51,1981$.

S. P. Pappas, "On the selection of latent catalysts and reactants for optimizing ambient stability and cure schedules of high solids coatings", High Solids Coatings, 8, 2-5, 1983.

S. P. Pappas and H-B. Feng, "Latent curatives for thermaliy-induced cationic polymerization", Cationic Polymerization and Related Processes, ISBN 12.287470.6, 1984.

D. Y. Perera and D. Vanden Eynde, "Solvent influence on the development of internal stress in a thermoplastic coating", J. Coat. Tech., 55, 37, 1983.

A. E. Rheineck and R. O. Austin, "Drying oils - modification and use", Chapter 4 in "Film Forming Compositions", Vol. 1, Part II, Marcel Dekker, New York, 1968.

R. P. A. Sims and W. H. Hoffman, "Oxidative polymerization", Chapter 15 in "Autoxidation and Antioxidants", $\omega$. 0 . Lundberg, Ed., Vol. 2, Wiley-Interscience, New York, 1962.

D. H. Solomon, "The Chemistry of Organic Film Formers", Wiley, New York, 1967, and 2nd ed., Krleger, Huntingdon, NY, 1977.

D. H. Solomon and D. G. Hawthorne, "Chemistry of Pigments and Fillers", Wiley-Interscience, New York, 1983.

W. S. Stoy and T. G. Brown, "Extenders: coatings" inorganic backbone", Mod. Paint Coatings, October, 162, 1982.

M. Teffal and A. Gourdenne, "Activation of radical polymerization by microwaves. I. Polymerization of 2-hydroxyethyl methacrylate", Eur. Polym. J., 19, 543-9, 1983. 
S. K. Wason and J. W. Maisel, "Thixotropic properties of new precipitated silica in gel coats". Proc. 36th Annual Conference, Soc. Plast. Industry, Section 13-C, 1, 1981.

S. K. Wason and J. W. Maisel, "Evaluation of new precipitated sllica thixotrope in plastics", Proc. 38th Annual Conference, Soc. Plast. Industry, Section 3-F, 1, 1983.

B. C. Watson and 2 . W. Wicks, "Popping of water-soluble acrylic coatings", J. Coat. Tech., 55, 59, 1983.

H. Wexler, "Polymerization of drying olls", Chem. Rev., 64, 591,1964 , and references therein.

G. C. Whitaker, "Driers and metallic soaps", Encyclopedia of polymer science and technology", volume 5, wiley, New York, 1966.

2. W. Wicks, E. A. Anderson, and W. I. Culhane, "Morphology of water-soluble acrylic copolymer solutions", J. Org. Coat. Tech, $54,57,1982$. 



\begin{tabular}{|c|c|c|c|}
\hline $\begin{array}{c}\text { U.S. OEPT. OF COMM. } \\
\text { BIBLIOGRAPHIC DATA } \\
\text { SHEET (See instructions) }\end{array}$ & $\begin{array}{c}\text { 1. PUBLICATION OR } \\
\text { REPORT NO. } \\
\text { NBSIR } 85-3216\end{array}$ & 2. Performing Organ. Report No. 3. Publication Date & SEPTEMBER 1985 \\
\hline
\end{tabular}

4. TITLE AND SUBTITLE

Intaglio Ink Considerations

5. $A \cup T H O R(S)$

B. Dickens

6. PERFORMING ORGANIZATION (If joint or other than NBS, see instructions)

7. Contract/Grant No.

NATIONAL BUREAU OF STANDARDS

U.S. DEPARTMENT OF COMMERCE

GAITHERSBURG, MD 20899

9. SPONSORING ORGANIZATION NAME AND COMPLETE ADDRESS (Street. City. State, ZIP)

10. SUPPLEMENTARY NOTES

Document describes a computer program; SF-185. FIPS Software Summary, is attached.

11. ABSTRACT (A 200-word or less factual summary of most significant information. If document includes a significant bibliography or literature survey. mention it here)

Alkyds are recommended as the most practical resin system to polymerize in air. The alkyd should have a well-chosen molecular weight distribution and be dispersible in a water-containing solvent system. The solubility of oxygen in the ink formulations and solvent mixtures should be determined and the compositions adjusted to provide a level of oxygen which gives optimum cure. UV irradiation of the newly printed currenc, paper can probably be used to skin the ink rapidly and prevent blocking. This may allow printing of both sides of the currency paper in one pass. Replacement of the various pigments and fillers currently in use by dyes attached to the backbone of an organic polymer, either in water-soluble form or in the form of a glass should be investigated. The silica filler may be acting as a dessicant as well as a thickening agent. If this dessicant action is not important, thixotropy of the ink should be adjusted by using sodium carboxy methyl cellulose instead. Other recommendations are given and the formulation of intaglio printing inks is reviewed with special reference to BEP requirements.

12. KEY WORDS(Six to twelve entries; alphabetical order; capitalize only proper names; and separate key wores ty sem colors

Order From Superintendent of Documents, U.S. Government Printing Office, Washıngron, DC 20402.

XOrder From National Technical Information Service (NTIS), Springfield, VA 22161

14. NO. OF PRINTED DAGES

30

15. Peice 


